https://doi.org/10.7203/Normas.3.4679

\title{
DEL CASTELLANO DE «UN PEQUEÑO RINCÓN» AL ESPAÑOL INTERNACIONAL
}

\author{
FROM THE CASTILIAN OF “A SMALL CORNER” TO INTERNATIONAL SPANISH
}

\author{
Antonio TORRES TORRES \\ Universitat de Barcelona
}

\section{RESUMEN:}

Este artículo analiza, desde una perspectiva general, las grandes etapas que se han sucedido en la historia del español con respecto a la dinámica entre variación y norma(s). Se argumenta que, partiendo de la difusión de la lengua en el mundo, así como de los nuevos enfoques en la teoría lingüística, solo en las últimas décadas parece haberse alcanzado un modelo normativo que, sin dejar de lado la preocupación por la unidad del español, puede permitir el encaje de sus diversas normas; unas normas que, por otro lado, y más allá de las Academias, tienden a una nueva convergencia en los medios de comunicación masiva que afianzará la potencia del español ante los retos que se vislumbran.

PALABRAS CLAVE: lengua española, norma lingüística, pluricentrismo, panhispanismo, español internacional.

\section{ABSTRACT:}

This article discusses, from a general perspective, the major stages that have occurred in the history of the Spanish language with respect to the dynamics between variation and standard(s). Based on the language's diffusion around the world, as well as on current approaches to linguistic theory, it is argued that only in the last few decades has a regulatory model been reached that, without disregarding the concern for the unity of the Spanish language, can allow diverse standards to fit within a greater whole. Well beyond the scope of the Academies, these are norms that are inclined to lead toward to a new convergence in the mass media that will strengthen the power of the Spanish language to face future challenges.

KEYWORDS: Spanish language, linguistic norm, pluricentrism, panhispanism, International Spanish. 


\section{INTRODUCCIÓN}

Actualmente, el español, que nació en «un pequeño rincón» cántabro, tomando las palabras con las que se refiere a Castilla el conocido Poema de Fernán González, se ha convertido, como se sabe, en una de las grandes lenguas internacionales de comunicación. En este largo proceso, la relación entre unidad y variedad, entre norma y variación, ha pasado por distintos estadios, y representa un asunto crucial sobre el que se sigue debatiendo. Existen excelentes trabajos sobre la historia de la lengua española y análisis de gran valor sobre aspectos puntuales que atañen al monocentrismo, al pluricentrismo, a la relación entre cultura pluricéntrica y política linguística panhispánica o al español internacional. Sin embargo, se echa en falta la visión general, totalizadora, de cómo se ha contemplado en distintos momentos, y se contempla hoy, la dinámica entre diversidad de usos y norma(s) de referencia. A facilitar esa imagen de conjunto quiere contribuir el presente artículo.

Para ello, hemos tomado la referencia simbólica de unos versos del poema épico citado como punto de partida, y hemos trazado un recorrido crítico por los textos teóricos más representativos del estudio de la norma hispánica con el fin de establecer con claridad las principales etapas en la evolución de la idea del español «ejemplar»y en la concepción de cómo se articula la diversidad dentro de una lengua unitaria como es el español, desde la asunción previa de la ambigüedad que comporta hablar de «norma linguíística» y de los límites laxos del concepto. De este modo, establecemos el engarce que va de la norma monocéntrica para todo el mundo hispánico a la discusión sobre el futuro de la lengua tras las independencias americanas, el establecimiento del policentrismo, defendido por las Academias en paralelo al panhispanismo, y la nueva convergencia del español, ya en el terreno de los medios de comunicación globales, con el debate sobre los efectos que esa modalidad transnacional puede tener sobre la propia lengua. A la vez, valoramos las últimas posturas académicas, complementadas por la reestandarización internacional, como la mejor respuesta al problema del anclaje de las variedades en el conjunto de la lengua y de la aceptación de un «superestándar» que no es de nadie en particular, pero que es de todos.

\section{PERSPECTIVA HISTÓRICA}

En el Poema de Fernán González, compuesto a mediados del siglo XIII por un monje que pertenecía al monasterio de San Pedro de Arlanza, o bien escribía para él, se recoge la vida del primer conde de Castilla, del siglo $\mathrm{X}$, que liberó su región del vasallaje que le imponía León. Antes de centrarse en el relato épico de los hechos que protagonizó el legendario libertador, camino de la independencia de su condado, el poema describe cómo era Castilla, cuna del español, en aquellos tiempos (pp. 81-82):

Estonçe era Castiella un pequeño rincon,

NORMAS. REVISTA DE ESTUDIOS LINGÜÍSTICOS HISPÁNICOS, NÚMERO 3 (AÑO 2013):

http://www.uv.es/normas

(ISSN 2174-7245) 
era de castellanos Montes d'Oca mojon, e de la otra parte Fitero el fondon, moros tenien Caraço en aquesta sazon ${ }^{1}$. Era toda Castiella solo una alcaldia; maguer que era pobre $e$ de poca valia, nunca de buenos omnes fue Castiella vazia, de quales ellos fueron paresçe aun oy dia. Varones castellanos, este fue su cuidado: de llegar su señor al mas alto estado; d'un alcaldia pobre fizieron la condado, tornaron la despues cabeça de reinado.

El castellano, nacido en esa región cantábrica, va adquiriendo durante la edad media la condición de koiné, de instrumento de comunicación, entre los pueblos de la península ibérica, y de lengua de cultura. Se puede considerar la fecha de 1252, año en que subió al trono Alfonso X el Sabio, como el arranque simbólico de la tarea de estabilización formal, de codificación, para el castellano, aunque el modelo alfonsí tuviera un alcance limitado. Asimismo, es necesario recordar la ayuda que supuso la llegada de la imprenta en la difusión de la lengua, la relevancia de la Gramática de la lengua castellana, de Antonio de Nebrija, que apareció en Salamanca en agosto de 1492, donde lengua y poder político se imbrican fuertemente, y de sus diccionarios bilingües español-latín y latín-español —obras, todas ellas, muy criticadas en el Diálogo de la lengua (1535), de Juan de Valdés-, o el hito que marca el Tesoro de la lengua castellana o española (1611), de Sebastián de Covarrubias Horozco. Sin embargo, las intervenciones más decisivas en la historia del español han venido de la mano de la Real Academia Española, creada en 1713, que representa la institucionalización de las decisiones lingüísticas, con una base, durante un largo periodo, de naturaleza monocéntrica.

Entre los siglos XIII y XVI, Toledo representó el modelo de lengua en Castilla, el referente de prestigio para el buen hablar ${ }^{2}$. Moreno Fernández (2005: 112) traza los rasgos generales que debieron de caracterizar esa modalidad:

La diversidad sociolingüística de la Toledo medieval debió ser fascinante y la conjunción de elementos tan diversos debió favorecer algunas soluciones lingüísticas que

\footnotetext{
${ }^{1}$ Castilla limitaba «por los Montes de Oca, cordillera al NE. de la ciudad de Burgos, con el reino de Navarra; Hitero del Castillo, situada a pocos kilómetros al oeste de Castrogeriz, y sobre el Pisuerga, era la frontera con León. Por el N., hay que suponer que limitaba con el mar. Finalmente, en la frontera del S. y SE., hay que tomar como divisoria con el territorio musulmán la cuenca del Duero: Carazo está situada a pocos kilómetros al S. de Salas. Así pues, si se exceptúa la frontera septentrional, los límites expresados indican que el antiguo condado castellano no rebasaba los actuales de la provincia de Burgos.

»Independientemente de la veracidad histórica de estos límites, es obvio que el Arlantino tiene todo interés en presentar un condado pequeño [...] para realzar su auge posterior» (Poema de Fernán González, ed. de Juan Victorio, p. 81, nota n. ${ }^{\circ} 171$ ).

${ }^{2}$ Vergara (1986 [1936]: 408) aún recogía la paremia «Lengua castellana en boca toledana», que interpretaba así: «Parece indicar que en Toledo es donde mejor se habla el idioma oficial de España; sin embargo, otros opinan que lo hablan con más pureza en Valladolid».
} 
distinguieron su castellano respecto del de otras ciudades más norteñas. Las posibilidades de innovación, sin embargo, encontraron sus límites con la consolidación de la ciudad como centro de la Corte y como foco de cultura y de prestigio sociocultural, rasgos que acentuaron su conservadurismo lingüístico.

Con el traslado de la Corte a Madrid, ordenado por Felipe II en 1561, después de un periodo de transición en Valladolid, la vieja norma toledana fue entrando en decadencia y las hablas castellanas norteñas «se convirtieron en el XVII no sólo en las más ampliamente utilizadas, sino también en el modelo de referencia para la norma cuidada del español, en detrimento del castellano de Toledo» (Moreno Fernández, 2005: 140). Entretanto, el habla de Sevilla, con una personalidad definida desde la baja edad media, y en atención a la relevancia económica y cultural de la ciudad hasta el siglo XVIII, fue adquiriendo el papel de norma de referencia en su ámbito, y expandió su cuño por el sur de la Península, Canarias y muchos territorios de América.

Lara (2005), que explora la dimensión simbólica del español, la evolución y las características de la «idea de la lengua» española, pero no desde su centro, sino desde el margen americano y mexicano, sostiene que con Carlos III y la influencia del despotismo ilustrado francés, el español se convierte por primera vez en un símbolo nacional de España: «El paso de la idea de la lengua española al imaginario colectivo que sustenta el Estado español desde Carlos III es anterior a la difusión del pensamiento nacionalista, de principios del siglo XIX, propalado por la Revolución Francesa» (Lara, 2005: 178).

Hasta hace pocas décadas, con algunas derivaciones que alcanzan el momento actual, la variedad castellana del español se consideró el referente universal del buen uso de la lengua. Como indica Garatea (2006: 144-145), la modalidad americana «no fue apreciada en relación de igualdad con la peninsular [...]. Buena cantidad de testimonios afirma que el español hablado fuera de España es menos puro y elegante», en un sentimiento que también adoptaron muchos nativos americanos. Y, a pesar de que la autonomía política de las colonias americanas de España tras la independencia «alentó una nueva aproximación a la lengua y nuevos juicios sobre los usos» (Garatea 2006: 145), con argumentos de marcado tinte antiespañol, sobre todo en la generación de 1837 en Argentina, «la codificación y normalización peninsular [...] continuó siendo la única codificación válida del español; es decir, se mantuvo el carácter monocéntrico, como en los siglos anteriores [...]. Ejemplo singular de ese monocentrismo es que sólo a mediados de 1950, la Real Academia dejó de considerar el seseo como vicio de dicción» (Garatea, 2006: 146) ${ }^{3}$.

${ }^{3}$ Esto no quiere decir, sin embargo, que la situación del periodo colonial se mantuviera incólume a partir de la ruptura política: «no se puede negar que muchos aspectos de la realidad lingüística que se había ido constituyendo a lo largo de tres siglos tenían mayor ocasión de salir a la superficie en el contexto de la América emancipada, y que los estímulos externos podían actuar en el ámbito del lenguaje de un modo menos homogéneo que antes» (Rivarola, 2006: 102).

NORMAS. REVISTA DE ESTUDIOS LINGÜÍSTICOS HISPÁNICOS, NÚMERO 3 (AÑO 2013):

http://www.uv.es/normas

(ISSN 2174-7245) 


\section{UNIDAD Y DIVERSIDAD DEL ESPAÑOL}

Un punto de partida fundamental al que atiende López García (2010: 34) es que, mientras que para los lingüistas las lenguas se definen como sumas o intersecciones de rasgos (los dialectólogos las entienden como la suma de sus variedades diatópicas, diastráticas y diafásicas; los gramáticos, como una intersección de las propiedades de todos sus dialectos), para los hablantes se suelen concebir como prototipos. Si se aplican los principios de la teoría de prototipos al español, se sigue que «lo que llamamos lengua española no es una realidad objetiva, sino una categoría mental prototípica a la que adscribimos todas sus variedades dialectales», que «no todas las variedades son igualmente ejemplares, el español de Valladolid se siente por los hablantes más cerca del prototipo que el de Malabo, por ejemplo», y que «los límites son borrosos, no es evidente cuándo los habitantes de la raya fronteriza entre Uruguay y Brasil están hablando español o portugués», entre otras constataciones (López García, 2010: 35).

Desde Andrés Bello y Rufino José Cuervo, la unidad del español representa un motivo constante de reflexión y de preocupación. Se continúa discutiendo si en el mundo hispanohablante hoy pesan más las fuerzas centrípetas de cohesión o las centrífugas de fragmentación. Como afirma Torrent-Lenzen (2006: 64), existe

un sincero interés por el mantenimiento de una unidad lingüística [...] porque existe un sentimiento de comunidad lingüística hispánica, que se define como ente homogéneo y diverso a la par, y porque existen también unos valores lingüísticos sobre los que descansa nuestra identidad. El más claro exponente de esta sincera voluntad por mantener una unidad lingüística es el mismo hecho de que el tema de la unidad siga despertando tanto interés.

Es evidente, no obstante, que la relación que debe existir entre unidad y diversidad de la lengua no se conceptúa siempre de la misma forma. Lara (2005: 182) indica que aún predomina una concepción centralista metropolitana del español,

incapaz hasta ahora de replantear ni la historia canónica de la lengua, que sigue la pauta definida por Ramón Menéndez Pidal (manifiesta, en especial, en la Historia de la lengua española de Rafael Lapesa; primera edición: 1942), y la presenta como una historia patriótica, providencialista y castellanista, ni de tomar en consideración la existencia y las características de las variedades del español en la península y en América que se han producido a lo largo de los siglos.

Garatea (2006: 148) entiende que existe una lengua literaria «relativamente homogénea y unida» que se superpone a lo que llama «varias lenguas estándar»o «estándares nacionales o regionales», en «un equilibrio entre la unidad de la época colonial y la fragmentación del período independiente», por lo que, a su juicio,

debe rechazarse cualquier afirmación que pretenda justificar un ideal de lengua para toda la comunidad hispanohablante, porque esta idea, propia del período colonial, además de

NoRMAS. REVISTA DE ESTUdIOS LINGÜÍSTICOS HISPÁNICOS, NÚMERO 3 (AÑO 2013):

http://www.uv.es/normas

(ISSN 2174-7245) 
inaceptable, es falsa. Que existe un ideal de lengua es cierto, que en él pueden reconocerse formas comunes también lo es; pero igualmente cierto es que ese ideal no es el mismo para todos y que, con más frecuencia de lo que se admite, muchos rasgos nacionales o regionales son considerados «ejemplares» por sus hablantes, aún [sic] cuando tienen un limitado espacio de vigencia.

Sin embargo, parece perfectamente compatible la existencia de varias «ejemplaridades» con el afianzamiento de un ideal de norma panhispánica, enriquecido, como luego veremos, por el «español internacional» (cf. Pöll, 2012: 40-41).

\section{EL CONCEPTO DE NORMA LINGÜÍSTICA}

Como es sabido, el concepto de norma lingüística presenta una marcada ambigüedad, puesto que encierra dos vertientes: por una parte, el uso, la realización habitual, la conciencia lingüística de los hablantes, y, por otra, el modelo institucionalizado, la prescripción que debe seguirse. La norma social selecciona los rasgos compartidos por el mayor número de hablantes, en tanto que la normativa oficial es un subconjunto de la norma anterior, algo así como «una norma social filtrada por el prototipo culto de la sociedad» (López García, 2010: 74). Así pues, la norma que dictan las Academias se nutre cada vez más del uso y, dentro del dinamismo que la caracteriza, se va ensanchando paulatinamente merced a una política panhispanista que, con todo, no rompe ostentosamente con la tradición. En palabras de Torrent-Lenzen (2006: 186), «[1]a norma es [...] el resultado de un proceso de abstracción, en el cual es objetivado el uso consagrado en una comunidad lingüística determinada, objetivación que, a su vez, actúa como modelo y punto de referencia en las actividades y en la conciencia lingüísticas de los usuarios». Sea como sea, los debates sobre la norma del español continúan, con posturas a veces difíciles de conjugar y teñidas en ocasiones de ideología (Fajardo, 2011: 55-57). También es necesario advertir que la norma ejemplar no es una entidad discreta, sino gradual, con distintos niveles a lo largo de una escala (Borrego, 2004: 66-67).

\section{EL ESPAÑOL, LENGUA PLURICÉNTRICA}

El sociolingüista norteamericano William A. Stewart es quien emplea por primera vez, en un artículo de 1968, el concepto de pluricentrismo o policentrismo (Pöll, 2012: 31), que después popularizarán Heinz Kloss, en 1978, y Michael Clyne, quien en 1992 editó una obra fundamental para el establecimiento de los estudios referentes al pluricentrismo lingüístico ${ }^{4}$. Desde entonces el interés por este tema no ha parado de crecer y, además, lo ha hecho desde disciplinas variadas. Precisamente, diferentes

\footnotetext{
${ }^{4}$ En esa obra, Thompson (1992) presenta el español como una lengua pluricéntrica, y distingue cinco centros de prestigio lingüístico en América y tres en España.
}

NORMAS. REVISTA DE ESTUDIOS LINGÜÍSTICOS HISPÁNICOS, NÚMERO 3 (AÑO 2013):

http://www.uv.es/normas

(ISSN 2174-7245) 
investigadores constatan que el español - lengua plurinacional, expresión de culturas muy diversas en un gran número de territorios - se caracteriza actualmente por el pluricentrismo, esto es, por contar con varias modalidades de referencia, varios centros de prestigio interactivos, cada uno de los cuales tiene validez normativa ${ }^{5}$, en un equilibrio similar al que encontramos en portugués o en inglés, frente - por ejemploal francés, lengua pluricéntrica asimétrica (Torrent-Lenzen, 2006: 198-200; Garatea, 2006: 151-153) ${ }^{6}$. Lara (2005: 184) describe este español pluricéntrico como

un dinámico conjunto de españoles nacionales, regionales históricos (por ejemplo, el andaluz occidental, el antillano, el centroamericano, el rioplatense, el yucateco), y regionales modernos, creados por las comunidades nacionales de comunicación (por ejemplo, el andaluz sevillano actual, el español catalán, el andino, el del centro de México; incluso el que hablan indios mexicanos bilingües, influido por sus lenguas maternas), que alteran su antigua constitución. Pero además de «pluricéntrico», el español actual es «multipolar», pues algunas de esas variedades nacionales o regionales son, también, focos de irradiación de características lingüísticas y de normas de corrección, difundidas por su prestigio socio-político y sus medios de comunicación.

Es indiscutible que determinar cuáles son exactamente esos modelos irradiadores de norma constituye un reto para los investigadores, y que, en su mayor parte, como advierte Rivarola (2006: 105), «las normas en cuestión son de carácter "subyacente", para adaptar un término usado por Mattheier, es decir, que no tienen una codificación explícita, a pesar de lo cual son reconocidas como tales por lo[s] hablantes de las correspondientes variedades y tienen un carácter implícitamente prescriptivo». Un paso determinante fue el proyecto de estudio coordinado del habla culta manejada en las principales ciudades del orbe hispánico, lanzado en 1964, y del que se han publicado muchos materiales e investigaciones; asimismo, numerosos proyectos actuales de

${ }^{5}$ López García (2010: 64-65, 90) plantea la conveniencia de diferenciar entre pluricentrismo (con prefijo latino) y policentrismo (con prefijo griego). Por el primero se entiende que una lengua presente variedades diatópicas claramente diferenciadas, y por el segundo - que presupone el primero- que dicha variación se reconozca oficialmente en forma de normativas alternativas que la recojan. Y, como sucede en el caso del español, «una lengua puede perfectamente ser pluricéntrica al tiempo que sus elites pueden mostrar notables resistencias para configurarla normativamente como policéntrica» (López García, 2010: 90). Dentro de la teoría de prototipos, existen dos modelos formales básicos, el de prototipo centrado —el clásico - y el de prototipo difuso — que se basa en los parecidos de familia - . El primero estructura la normativa histórica, y el segundo, la normativa policéntrica (López García, 2010: 76-77, 88-92). De acuerdo con el investigador citado, los dos prototipos se dan a la vez en español.

${ }^{6}$ Con una visión distinta de la situación del español con respecto a esas otras lenguas, Di Tullio (2007: 15), de la Academia Argentina de Letras, subraya lo siguiente: «A diferencia del francés, lengua monocéntrica, y del inglés o del portugués, lenguas claramente bicéntricas, con un centro europeo y uno americano, la representación del español poscolonial es la de una lengua pluricéntrica, idealmente formada por tantos centros como capitales nacionales». Sea como sea, dentro del pluricentrismo no existe una simetría absoluta entre los centros. Precisamente, y desde una concepción no dicotómica, sino gradual, del pluricentrismo, Pöll (2012: 33-34) asume que «el español se caracteriza por un pluricentrismo asimétrico, sin duda más asimétrico que el inglés y de todas formas menos asimétrico que el francés». Resulta evidente que aún no se ha alcanzado un consenso acerca de lo que implica el carácter pluricéntrico del español.

NORMAS. REVISTA DE ESTUDIOS LINGÜÍSTICOS HISPÁNICOS, NÚMERO 3 (AÑO 2013):

http://www.uv.es/normas

(ISSN 2174-7245) 
estudio del español en todo el mundo resultarán decisivos, como Varilex (Ueda, 2009), Dispolex o PRESEEA ${ }^{7}$.

Todo ello supone preservar el valor de la unidad de la lengua, pero sobre unos pilares que se alejan del monocentrismo anterior. Como indica Torrent-Lenzen (2006: 199), «[e]l pluricentrismo une y separa, mantiene una unidad al mismo tiempo que respeta las diferencias nacionales y regionales constitutivas de una identidad». La unidad, en esta nueva concepción de la lengua, no se articula alrededor de un único modelo, sino en torno a una multiplicidad de polos que contribuyen a hacer del español un medio de comunicación eficaz para toda la comunidad hispanohablante. Así lo expresa Lara (2005: 185):

Una idea de la lengua acorde con esa realidad contemporánea del español necesita seguir orientándose por el valor de la unidad de la lengua, como principal medio de comunicación entre todos los hispanohablantes; pero no una lengua «unificada» por ninguno de sus centros o de sus polos, sino en constante regeneración por sus tradiciones escritas — centrípetas - y habladas — centrífugas - . Algo que se puede lograr, gracias a los actuales medios de comunicación y a la educación.

Asimismo, Rivarola (2006: 107) defiende los beneficios del pluricentrismo como antídoto frente a los fantasmas de la fragmentación linguística:

Una codificación que ignore las alternativas de lengua estándar que se manifiestan en el espacio de su vigencia corre el severo riesgo de no ser aceptada y fracasar en su pretensión de ser instrumento de unidad y consolidación idiomática. En cambio, el pluricentrismo normativo puede ser un factor de integración y favorecer en los hablantes el interés por otros modelos de lengua, así como estimular en ellos una cierta competencia plurilectal.

\section{EL PANHISPANISMO DE LAS ACADEMIAS}

Desde finales del siglo XIX, en que se funda la mayor parte de las Academias americanas, hasta mediados del siglo XX, estas no tuvieron casi ninguna incidencia sobre la configuración normativa del español. Pero se produce un cambio fundamental con la creación de la Asociación de Academias de la Lengua Española. El sistema de trabajo que se sigue para elaborar las obras normativas se puede estructurar en tres fases

${ }^{7}$ López García (2010: 64) relaciona con cuestiones neurolingüísticas la aceptación y valoración positiva del pluricentrismo léxico, frente a la extrañeza que produce, según el estudioso, el pluricentrismo fonético y gramatical: «Los hablantes de una lengua pluricéntrica son conscientes del léxico de los demás dialectos de manera parecida a como el oyente comprende palabras de su propio dialecto que no usaría nunca. Por el contrario, las peculiaridades gramaticales suelen ser ajenas a la conciencia de dichos hablantes de lenguas pluricéntricas, les sorprenden cuando las advierten y generalmente las rechazan. Otro tanto cabe decir de las peculiaridades fonéticas, de las que muchas se les escapan y unas pocas son motivo de parodia ("acento andaluz", etc.). Tampoco los oyentes suelen reconocer la variación fonética ni la variación gramatical dentro de su propio dialecto».

NORMAS. REVISTA DE ESTUDIOS LINGÜÍSTICOS HISPÁNICOS, NÚMERO 3 (AÑO 2013):

http://www.uv.es/normas

(ISSN 2174-7245) 
a partir de entonces (Süselbeck, 2012: 277): 1) de 1951 a 1965, en que apenas existe colaboración entre las Academias; 2) de 1965 a 2000, con la intermediación de la Comisión Permanente como coordinadora entre la RAE y el resto de Academias (a pesar de la presencia de delegados no españoles en Madrid, las decisiones finales se siguen tomando en el seno de la RAE); 3) de 2000 hasta hoy, en que, con el proyecto del Diccionario panhispánico de dudas, se pone en marcha una forma de trabajo democrática que permite a todas las instituciones acceder a una participación real en el proceso, en igualdad jerárquica.

Como indica Torrent-Lenzen (2006: 70), «a lo largo de la historia los criterios de corrección se han ido modificando en favor de una norma panhispánica pluricéntrica», que asume la diversidad de normas cultas en el conjunto del español, y que, en su búsqueda de equilibrio entre unidad y variedad, dicta modelos lingüísticos de referencia únicos pero flexibles, aplicables esencialmente a los usos escritos. En palabras de Moreno Fernández (2010: 99), «[1]a estandarización del español es de naturaleza "monocéntrica" (norma académica única) construida sobre una realidad polinormativa (norma culta policéntrica)». Las Academias de la Lengua Española defienden actualmente de modo explícito una política linguística panhispánica que dibujan en los términos siguientes:

Una tradición secular, oficialmente reconocida, confía a las Academias la responsabilidad de fijar la norma que regula el uso correcto del idioma. Las Academias desempeñan ese trabajo desde la conciencia de que la norma del español no tiene un eje único, el de su realización española, sino que su carácter es policéntrico. Se consideran, pues, plenamente legítimos los diferentes usos de las regiones lingüísticas, con la única condición de que estén generalizados entre los hablantes cultos de su área y no supongan una ruptura del sistema en su conjunto, esto es, que ponga en peligro su unidad ${ }^{8}$.

A pesar de todo, Di Tullio (en Lagares/Celada, 2011: 103-104) indica la falta de coherencia

entre lo que se enuncia y los resultados concretos. Esto es particularmente notorio en el Diccionario Panhispánico de dudas (2005), la obra normativa por excelencia de la RAE. A pesar de declararse panhispánica, la marca de la incorrección, la bolaspa, recae en un

8 Presentación en la página web de la Real Academia Española, <http://www.rae.es/rae $\% 5 C$ Noticias.nsf/Portada4?ReadForm\&menu=4>. En la misma línea se manifiesta en el «Prólogo» de la Nueva gramática de la lengua española su director, Bosque (2009: XLII), donde asume el «principio de que la norma tiene hoy carácter policéntrico. La muy notable cohesión linguiística del español es compatible con el hecho de que la valoración social de algunas construcciones pueda no coincidir en áreas lingüísticas diferentes. No es posible presentar el español de un país o de una comunidad como modelo panhispánico de lengua. Tiene, por el contrario, más sentido describir pormenorizadamente las numerosas estructuras que son compartidas por la mayor parte de los hispanohablantes, precisando su forma, su significado y su estimación social, y mostrar separadas las opciones particulares que pueden proceder de alguna variante, sea del español americano o del europeo. Cuando estas opciones resultan comunes, y hasta ejemplares, en áreas lingüísticas específicas, deben ser descritas como tales. Obrar de este modo no solo no pone en peligro la unidad del español, sino que contribuye más bien a fortalecerla, y ayuda a comprender su distribución geográfica de forma más cabal».

NORMAS. REVISTA DE ESTUDIOS LINGÜÍSTICOS HISPÁNICOS, NÚMERO 3 (AÑO 2013):

http://www.uv.es/normas

(ISSN 2174-7245) 
porcentaje mayoritario sobre fenómenos propios del español de América, sin que se controle si se trata de un fenómeno estigmatizado en la comunidad lingüística o no.

Y critica que se consideren incorrectas formas como el uso del adjetivo policial en cuento o novela policial, frente a cuento o novela policiaco, o la construcción se los / se las (Esto ya se los dije), que manejan muchos hablantes americanos de todos los niveles socioeducativos.

Del mismo modo, Méndez García de Paredes (2012) escribe que, frente a la imagen que puede tener un usuario del Diccionario panhispánico de dudas al realizar una consulta, un análisis del cuerpo textual de la obra descubre que

[1]a nueva orientación dada a la codificación no termina de consolidarse en esta primera obra de conjunto, pese a la participación de todas las Academias americanas. No solo el cómputo real de ejemplos se inclina proporcionalmente del lado de la antigua metrópolis, sino que la concepción monocéntrica de la norma sigue, inconscientemente, solapada en la perspectiva enunciativa que se asume en la exposición metalingüística. El español de España sigue siendo referencia y medida para la variación, pues lo particular, o lo menos frecuente, o la condescendencia normativa ante un uso, por el hecho de que está ampliamente extendido o se da entre hablantes cultos, suele hacerse corresponder con empleos americanos (Méndez García de Paredes, 2012: 290-291).

De acuerdo con la investigadora, los desajustes conceptuales en las nociones de pluricentrismo y de panhispanismo llevan a debilidades en la exposición y en las recomendaciones normativas del $D P D$, y sugiere que se revisen los criterios de valoración y aceptabilidad manejados. No obstante, observa un rumbo renovado en la Nueva gramática de la lengua española (2009), en la que

parece haberse dado un cambio ideológico con respecto al DPD en el tratamiento discursivo que se da a muchos fenómenos censurados con bolaspa en la primera obra normativa de las Academias. Esto es, se ha procurado aquilatar mucho la manera de decir. Ya no subyace en la exposición esa mirada eurocéntrica, rectora de la norma que concede carta de naturaleza normativa a algunas construcciones no usadas en la Península, de ahí que lo americano ya no parezca constituir lo particular, lo arcaico, lo que ha caído en desuso (Méndez García de Paredes, 2012: 309).

Desde el punto de vista lexicográfico general, y frente a la apelación a lo «nacional» que se hace, por ejemplo, en el Diccionario del español de México, dirigido por Luis Fernando Lara, el Diccionario de americanismos (2010), dirigido por Humberto López Morales, constituye una «contribución fundamental para el avance en la definición de una norma lingüística hispánica», pues aunque se presenta como una obra descriptiva, «el hecho de haberse convertido en el diccionario de americanismos del español por antonomasia le otorga un poder de referencia que indudablemente tendrá consecuencias en la configuración normativa de nuestra lengua» (Fajardo, 2011: 64). 
Por su parte, José Luis Moure (en Lagares/Celada, 2011: 105), de la Academia Argentina de Letras (como académico de número), entiende que el panhispanismo es «antes que una demanda real de los usuarios de la lengua, un constructo peninsular, económicamente recomendable para hacer más viable cierta unidad de la industria editorial o del doblaje». Lo mismo se propone, como veremos más abajo, con respecto al español internacional.

\section{EL ESTATUS INTERNACIONAL DEL ESPAÑOL Y SU POTENCIA ECONÓMICA}

La globalización que vivimos también tiene una faceta lingüística; todas las lenguas se ven afectadas por ella, puesto que unas se usan más y otras pierden relevancia (Garrido, 2010). En la actualidad, el español tiene presencia en las organizaciones internacionales ${ }^{9} \mathrm{y}$, por detrás de un inglés cómodamente hegemónico, posee el carácter de segunda lengua de comunicación internacional ${ }^{10}$, a lo que contribuye su creciente demografía (I), la notable cantidad de países en los que se utiliza (II) y su destacada homogeneidad (III).

(I) Como recoge el último informe del Instituto Cervantes (2012), el español es la segunda lengua más hablada del mundo como lengua nativa, después del chino mandarín, que supera los 1000 millones de usuarios ${ }^{11}$. En sus facetas de lengua nativa, segunda y extranjera, manejan el español más de 495 millones de personas, y se estima que en 2030 el número de hispanohablantes será de 535 millones, lo que representará el 7,5 \% de la población del planeta. Por otro lado, las estimaciones sobre el número de estudiantes de español como lengua extranjera, en todos los niveles de enseñanza, apuntan a unos 18 millones de alumnos.

(II) Se extiende por España, México, Guatemala, El Salvador, Honduras, Nicaragua, Costa Rica, Panamá, Cuba, República Dominicana, Puerto Rico (cooficial con el inglés), Venezuela, Colombia, Ecuador, Perú, Bolivia, Paraguay (cooficial con el

\footnotetext{
${ }^{9}$ Como indica Marcos-Marín (2006: 33), «el español es una de las lenguas de las Naciones Unidas y los organismos que de ella dependen o con ella se relacionan, como UNESCO. La condición de lengua oficial de la Unión Europea, teóricamente imprescindible, se enfrenta a una realidad inevitable: la dispersión e incoherencia lingüística de Europa». En contraste con el siglo XVI y las primeras décadas del siguiente, cuando el peso del español era determinante en Europa, hoy ocupa un lugar muy secundario en el viejo continente.

${ }^{10}$ Aunque con una proyección insuficiente en los ámbitos de la diplomacia, de la ciencia y de la técnica. Como escribe Garrido (2010: 90), «la élite universitaria y científica se comunica (y se constituye) en inglés». Por contra, el español disfruta de un carácter internacional en Internet, donde es la tercera lengua más utilizada (8\% del total), por detrás del inglés $(38 \%)$ y del chino $(22 \%)$. De media, usa Internet en Latinoamérica el 39,50 \% de la población, lejos del 71,5 \% de la Unión Europea y del 65,6 \% de España, pero Argentina, con el $67 \%$, supera a este último país, y otros se le acercan, como Chile $(59,20 \%)$ o Uruguay $(56,10 \%)$. España y México están entre los veinte países con el mayor número de internautas (Instituto Cervantes, 2012).

${ }^{11}$ López Morales (2010: 217) señalaba que el español era la cuarta lengua más hablada del mundo, con unos 400 millones de usuarios (el 5,7 \% de la población), después del chino mandarín (1200 millones), el inglés (478 millones) y el hindi/urdu (437 millones).
} 
guaraní), Chile, Argentina y Uruguay. Es cooficial con el francés y el portugués en Guinea Ecuatorial. Además, se ha fortalecido en los Estados Unidos, así como en el sistema educativo de Brasil, miembro de la alianza económica Mercosur junto con Bolivia, Chile, Paraguay, Argentina y Uruguay. En Belice, cuya lengua oficial es el inglés y donde funciona como lengua franca el criollo beliceño, de base inglesa, el español constituye la lengua nativa de casi el $50 \%$ de la población (128 643 hablantes en una cifra total de 285000 habitantes) y la segunda de otro $20 \%$ (López Morales, 2010: 229-232). En Trinidad y Tobago, donde también el inglés es la lengua oficial, se realizan esfuerzos por asentar la enseñanza del español, habida cuenta del entorno hispanohablante en el que se sitúan las islas, muy próximas a Venezuela. Por otro lado, queda una tímida presencia del español en el norte de África y en puntos de la región Asia-Pacífico. Finalmente, en distintos lugares del mundo permanecen algunas huellas del judeoespañol ${ }^{12}$.

(III) Se ha defendido también la unidad esencial del español, dentro de su diversidad, en lo que se refiere al conjunto de los niveles lingüísticos, incluso el léxico, una buena parte del cual es común a todos los hispanohablantes. Esto obedece, según López Morales, a la creciente internacionalización de la cultura actual:

La homogeneidad léxica que palpamos es el resultado — y lo será más— de la nivelación que va produciéndose por el vertiginoso crecimiento de las comunicaciones. Hay facetas de la cultura tradicional destinadas a refugiarse en zonas rurales, o quizá a perecer, con la consiguiente mortandad léxica. En cambio, muchos de los extranjerismos que por fuerza se aclimatan entre nosotros presentan una tendencia centrípeta, es decir, a la uniformación. Solo los neologismos autóctonos seguirán produciendo en lo futuro diferenciaciones léxicas de importancia (López Morales, 2010: 299).

Como explica Garrido (2010: 93), para el español, «la globalización conlleva un incremento en el contacto de los hablantes de diferentes variedades del español y de otras lenguas, en España y sobre todo en América, tanto en Estados Unidos como en otros países americanos».

Por otra parte, existe una estrecha relación entre el peso de una lengua y los índices macroeconómicos de los países en los que es oficial. Según estimaciones

${ }^{12}$ López García (2010) distingue entre Hispanidad (los países en los que el español es lengua materna), Hispanofonía («países en los que, si bien el español no es la lengua materna de la mayor parte de sus habitantes, éstos se mueven en su ámbito lingüístico con relativa fluidez», p. 136, como ocurre, en mayor o menor grado, con Guinea Ecuatorial, Filipinas, Andorra, Gibraltar, Israel o la región marroquí de Tetuán) e Hispanoproclividad (una nueva categoría semántica referida a «países en los que el español ni es lengua materna ni fue lengua colonial o fronteriza, pero lo están aprendiendo numerosas personas como segunda lengua impulsadas por ventajas de orden práctico», p. 137, como sucede prototípicamente en Brasil). En los Estados Unidos, el español presenta parcelas de Hispanidad (los cubanos de Miami), de Hispanofonía (Suroeste, Nueva York, Chicago) y de Hispanoproclividad (resto del país), pero en los hispanos predomina la segunda categoría, la Hispanofonía, no la Hispanidad: «Pasada la primera generación de inmigrantes, el español es una segunda lengua que no hablan como el inglés, en la que no se expresan la mayor parte de las representaciones cognitivas que constituyen su vida mental, pero de la que se sienten orgullosos y en cuyo espacio fónico les gusta sentirse integrados» (p. 140).

NORMAS. REVISTA DE ESTUdIOS LINGÜÍSTICOS HISPÁNICOS, NÚMERO 3 (AÑO 2013):

http://www.uv.es/normas

(ISSN 2174-7245) 
recogidas en el Anuario del Instituto Cervantes 2012 (Instituto Cervantes, 2012), el «PIB del español» se sitúa en los 4,5 billones de dólares en el mundo, dos tercios del cual se generan entre Norteamérica (México, Estados Unidos y Canadá) y la Unión Europea. Las actividades que giran en torno a la enseñanza del español, a las industrias culturales y al comercio son puntales de ese poder económico.

\section{EL LLAMADO ESPAÑOL INTERNACIONAL}

En su momento, la imprenta fue determinante para la estandarización de la lengua escrita; ahora, los nuevos medios de comunicación, que ejercen de timoneles en la difusión de los usos lingüísticos ${ }^{13}$, inciden básicamente sobre la lengua hablada: por aquí se llega a «la necesidad de usar un tipo de español considerado más internacional, que pueda emplearse en medios de diferente factura y que sea bien acogido por públicos de variada adscripción sociocultural y geográfica» (Bravo, 2008: 20) ${ }^{14}$. Este modelo no se enfrenta al ideal académico de norma panhispánica, sino que va más allá y lo enriquece.

\subsection{Español internacional y otras etiquetas}

Para aludir a esta modalidad ecléctica se utilizan distintas designaciones, que introducen matices singulares o connotaciones específicas. Una de las menos marcadas y de mayor circulación es la de español internacional, difundida por Raúl Ávila, que es la que presenta también mayores resonancias comerciales, como recogen Bravo (con esta denominación «[s]e resalta la internacionalidad como una virtud, un valor a favor de la difusión y la mejor aceptación de los productos, al tiempo que se garantiza una comprensión general y escaso índice de rechazo»; 2008: 28) y López Morales (Ávila «se refiere específicamente al [español] usado en los medios internacionales de comunicación que por fuerza buscan aquellos términos que sean $-\mathrm{o}$ que se crean que son-comprendidos con mayor facilidad por sus "clientes", cuantos más, mejor»; 2010: 423, en nota n. ${ }^{\circ}$ 6). Asimismo, se utilizan expresiones como español global, español universal, español mundial o, rodeada a veces de connotaciones peyorativas, y muy habitual, español neutro ${ }^{15}$. También se manejan designaciones menos marcadas como

13 «Los periodistas, los informadores por cualquier medio de comunicación, son difusores y propiciadores de usos lingüísticos» (Romero, 2008 [1993]: 12), por lo que recae sobre ellos una enorme responsabilidad en el buen manejo del idioma. Véase Aleza (2006).

${ }^{14}$ Gómez Font $(2012 a$ : 22; 2012b), coordinador general de la Fundación del Español Urgente (Fundéu), pone de relieve que es en los Estados Unidos donde resulta «más necesaria, y donde es más cotidiana», la «labor de búsqueda de un español común, neutro o internacional»: allí «se está gestando un nuevo español, un idioma que no es ni de los mexicanos ni de los argentinos, cubanos o centroamericanos, sino que es de todos». De hecho, el referente fundamental de esta norma es el canal televisivo CNN de Atlanta. Existe un Manual de estilo de la National Association of Hispanic Journalists (NAHJ), común para todos los medios de comunicación de los Estados Unidos que utilizan el español.

${ }^{15}$ Petrella (1997) analizó una ley argentina de 1986 que obliga a doblar al español neutro los productos audiovisuales elaborados en Argentina que se destinan a otros países hispanohablantes.

NORMAS. REVISTA DE ESTUDIOS LINGÜÍSTICOS HISPÁNICOS, NÚMERO 3 (AÑO 2013):

http://www.uv.es/normas

(ISSN 2174-7245) 
supradialecto estándar (Demonte, 2001) o tercera norma del español de América (Tejera, 2003) ${ }^{16}$.

\subsection{Rasgos del español internacional}

Se trata, según Tejera (2003: 863), de una «norma exógena», ya que ha sido creada artificialmente «fuera del ámbito natural de la lengua», y que «se parece mucho al español general, solo que este español no es una entelequia sino una realidad difundida por los medios a todos los lugares». En la configuración de esta modalidad «reestandarizada» se produce un desplazamiento del eje de referencia desde España hacia América, y se sigue un proceso de selección lingüística en todos los planos ${ }^{17}$. Ávila $(2001,2003)$ propone tender, frente a la «intimidad» del dialecto, esto es, la variación local del español, a una nueva convergencia general, elaborada entre todos los territorios del mundo hispánico y apoyada por los medios de comunicación masiva, los cuales ya están contribuyendo a ella por su propio interés. En primer lugar, se busca un acento neutro, «una entonación limpia de cualquier referencia, que no se pueda identificar con la de ningún país» (Bravo, 2008: 42). Con respecto a la pronunciación, se opta por el seseo y el yeísmo, y en el ámbito de la morfosintaxis no se usa el pronombre vosotros, -as, sino ustedes, se emplea tú (no vos) como tratamiento de confianza para la segunda persona del singular y usted para marcar respeto, se evitan el laísmo y el loísmo, y no se generaliza el leísmo de persona ni el de cortesía. Pero es el léxico el foco de actuación prioritario del español internacional.

Gómez Font (2012a: 20) indica que «nos interesa que los periodistas de los grandes medios de comunicación internacionales en español, cuando estén escribiendo sus informaciones, se pregunten de vez en cuando si lo que están poniendo podrán entenderlo todos los hispanohablantes». Cita como ejemplo la duda planteada al Departamento de Español Urgente de la Agencia EFE en 2004 con respecto a cuál sería la forma comprensible en todo el mundo hispánico para aludir a chabola, que ofrece muchas posibilidades de equivalencia (choza, chamizo, cabaña, tugurio, antro, cueva, refugio, cobijo, barraca, bohio, casucha, caseta, casilla, garita, rancho, favela, champa, etc.), y apunta que seguramente casucha es el sinónimo más fácil de entender, pero se decanta, como solución óptima, por el uso de una perífrasis: viviendas precarias (Gómez Font, 2012a: 20-21; 2012b).

No siempre el término escogido es el que utiliza un mayor número de hablantes, sino que puede corresponder al menos marcado o ambiguo. López Morales (2010: 427)

${ }^{16} \mathrm{Si}$ «[d]urante los siglos XIX y XX, el español de América siguió simultáneamente dos normas lingüísticas: una, la norma de España, que conocen y han conocido las personas cultas y que se ha usado lo más cerca posible en la lengua escrita; y otra norma, la que pertenece al país, a la ciudad o a la comarca americana, que se ha usado en la lengua hablada», hoy «estamos asistiendo a la aparición en América de una tercera norma que es el instrumento de expresión de los medios internacionales de comunicación de masas» (Tejera, 2003: 861, 862).

${ }^{17}$ Se pueden conocer los rasgos del español internacional o neutro en numerosos vídeos presentes en la red, como por ejemplo en Se habla español»: <http://www.youtube.com/watch?v=7CAkxvJjWm0\&feature=related>. [Consulta: 22/03/2013].

NORMAS. REVISTA DE ESTUdIOS LINGÜÍSTICOS HISPÁNICOS, NÚMERO 3 (AÑO 2013):

http://www.uv.es/normas

(ISSN 2174-7245) 
señala, por ejemplo, a partir de investigaciones del proyecto Varilex, que una palabra como auto/automóvil, aunque sea usada principalmente solo por el 36,5\% de los hablantes nativos, pertenece al español general, puesto que todos los hispanohablantes la comprenden, frente a otras como carro y coche, que significan cosas distintas en diferentes lugares (coche suele ser el de caballos en América, mientras que carro es el de tracción animal en España), o se usan en un territorio reducido (máquina, en Cuba y la República Dominicana).

En la nivelación del español juegan un papel fundamental los «culebrones» hispanoamericanos, las telenovelas, que, en su proceso de internacionalización, han ido prescindiendo de los regionalismos para favorecer la comprensión de todos. Además, las telenovelas, así como otros programas de televisión o de radio, y la lectura en papel o en Internet, amplían la nómina pasiva del léxico de los hispanohablantes, de modo que, por ejemplo, en Hispanoamérica es posible encontrar hoy en algunas partes un conocimiento pasivo de la palabra grifo, con el sentido de 'espita de agua', perteneciente al español europeo, y que se corresponde a distintas formas usadas allá, como caño, canilla, chorro, llave, pluma, etc. (López Morales, 2010: 434). Porque lo cierto es que todavía no se ha terminado de conformar la norma general hispánica, pues no todas las palabras del español tienen equivalente internacional. Ocurre, por ejemplo, con las que designan la 'pieza, generalmente en forma de aro, con la que el conductor dirige un vehículo automóvil': aunque volante es la más usada $(79,8 \%$ de los hablantes), no se comprende con facilidad en el resto de casos, en los que se recurre a voces como dirección, (el) guía, manubrio, manivela o timón (López Morales, 2010: 428).

Paralelamente, se produce un largo debate en torno a los efectos del español internacional. Para sus defensores, nos hallamos ante un modelo que surge de la cooperación, no de la imposición, que no emana de un grupo social dominante, y que tiene como misión conseguir una intercomunicación fluida en un español sin sello nacional o regional. Para sus detractores, constituye una lengua virtual, irreal, que al querer ser de todos no es de nadie, y que acarreará un empobrecimiento lingüístico en las generaciones venideras. No obstante, hay que tener en cuenta que, según el parecer de Tejera (2003: 873), «en la forma espontánea y oral de la lengua siempre existirán las diferencias, y que el dominio de la norma exógena sólo alcanza aquellos textos operativos donde la homogeneidad es un instrumento necesario que evita la ambigüedad y que pretende el entendimiento entre millones de hispanohablantes». En palabras de Bravo (2008: 59-60),

esta modalidad no pretende invadir la intimidad; tiene su ámbito de aplicación en contextos comunicativos informativos o ficticios, para hacer referencia a temas de actualidad, vida cotidiana, mundo empresarial, que deben ser transmitidos con un alto grado de fiabilidad. Nunca es un estilo previsto para la creación y sus defensores no creen, en modo alguno, que pueda sustituir a la variedad autóctona de cada país en la expresión de aspectos locales, familiares, sentimentales o creativos. 
Además, frente a casos como el ya mencionado de la CNN en español, la mayor parte de los medios utiliza la variedad de lengua de su lugar de origen, como Televisión Española Internacional, por lo que

no puede pensarse ni decirse que estemos todos constantemente bombardeados por ese español internacional $[\ldots]$ y que ello traerá consecuencias catastróficas para nuestra lengua, puesto que lo más visto y oído son —salvo excepciones- las producciones locales, y al margen de ellas, la programación de medios extranjeros que difunden en otros sitios su propia variedad idiomática (López Morales, 2010: 431-432).

López Morales no alberga duda acerca de que el vocabulario del español culto está unificado y, por tanto, entiende que lo que ocurre no es que los televidentes imiten el supuesto invento de las grandes cadenas de televisión, sino al contrario: los medios imitan la variedad culta del español, un español general con el que todos nos comunicamos.

Por otro lado, el español internacional tiene aplicación en la enseñanza del español, bien como primera lengua, bien como lengua extranjera, y el profesor debe conocer las bases de su funcionamiento para echar mano de ellas cuando sea necesario.

\section{CONCLUSIÓN}

Toledo y después Madrid representaron durante siglos el modelo de prestigio para el español. La variedad castellana ha tenido un papel nuclear en el conjunto de la lengua, que la Real Academia consagró en sus primeros siglos de labor, por lo que el resto de variedades del español, tanto en España como en América, debían reconocer un único centro generador de norma. Con la emancipación de las colonias americanas, la idea de «norma» también se fragmentó, se desataron las fuerzas centrífugas y se inició un debate que todavía hoy perdura sobre el futuro del español. En esa reflexión, prevalecen las voces que se decantan por el valor de la unidad, pero defendida cada vez más desde unos pilares distintos de los que sustentaban la rigidez del período colonial y aún más allá, pues se pone el acento en el pluricentrismo del español, esto es, en la consideración de que no existe un único centro rector y difusor de norma, sino muchos, a menudo identificados con las capitales de los países hispánicos.

Paralelamente, la institución académica se ha ido descentralizando en su funcionamiento interno y ha ido variando su política lingüística hacia el reconocimiento explícito del carácter pluricéntrico del español, de la existencia de distintas normas cultas en igualdad jerárquica, que algunos lingüistas llaman «estándares», a la vez que promueve el panhispanismo, el trabajo consensuado de las diferentes Academias con decisiones válidas para el conjunto de los hispanohablantes. Sin embargo, en el Diccionario panhispánico de dudas (2005) permanece aún, como han mostrado varios investigadores, un sesgo del viejo eurocentrismo, y es necesario esperar hasta la Nueva gramática de la lengua española (2009) para encontrar una obra académica que no solo predica la orientación pluricéntrica, sino que la practica en toda su amplitud. Esta

NORMAS. REVISTA DE ESTUDIOS LINGÜÍSTICOS HISPÁNICOS, NÚMERO 3 (AÑO 2013):

http://www.uv.es/normas

(ISSN 2174-7245) 
política debería contribuir a que todos los hispanohablantes se sintieran cómodos e incluidos en el modelo, lo que representa un beneficio para la unidad del español y, en consecuencia, para la consolidación de su poder en el mundo.

Precisamente en relación con este último aspecto, hemos ofrecido datos sobre la consolidación del español como lengua internacional, que se debe a su creciente número de hablantes, la extensión de países en los que se maneja y su marcada homogeneidad. No debe confundirse el estatus internacional del español con el llamado «español internacional», una de las designaciones más difundidas, junto con «español global», «español neutro» y otras, que inciden todavía más en la actual tendencia unificadora.

Gracias a las comunicaciones, los hispanohablantes están cada día más cerca y conocen mejor las variedades de su lengua, pero también se ha evidenciado la necesidad de un código supradialectal, ecléctico, producto de la convergencia general, que permita que el material elaborado por los medios de comunicación masiva en español pueda ser comprendido sin escollos por todos los hispanohablantes. Este código nivelado, que se superpone a las distintas normas cultas, puede ser un instrumento útil para acceder a cualquier contenido en español (somos, en general, receptores, pero no productores de esta variedad global), sin que la riqueza de la diversidad lingüística tenga que resentirse, ya que están bien compartimentados los entornos de uso de las distintas modalidades.

No obstante, queda por ver el grado de aceptación general que tendrá el español internacional, y hay que esperar que no se convierta en un motivo de escisión entre el español «latino» con el que muchos lo identifican y el «español de España».

\section{REFERENCIAS BIBLIOGRÁFICAS}

AlEZA IZQUIERDO, Milagros, coord. (2006): Lengua española para los medios de comunicación: usos y normas actuales, Valencia, Tirant lo Blanch.

ÁvilA, Raúl (2001): «Los medios de comunicación masiva y el español internacional», en II Congreso Internacional de la Lengua Española (Valladolid, 2001): <http://congresosdelalengua.es/valladolid/ponencias/unidad_diversidad_del_espanol/1_1 a_norma_hispanica/avila_r.htm>. [Consulta: 19/06/2013].

ÁvilA, Raúl (2003): «La lengua española y sus variantes en los medios de comunicación masiva», en Ávila, Raúl et alii, Pautas y pistas en el análisis del léxico hispano(americano), Madrid/Frankfurt, Iberoamericana/Vervuert, 11-25.

BORREGO, Julio (2004): «Norma hispánica y normas regionales en los medios de comunicación», en Perdiguero Villarreal, Hermógenes y Antonio Álvarez, eds., Medios de comunicación y enseñanza del español como lengua extranjera. Actas del XIV Congreso Internacional de ASELE, Burgos, Universidad de Burgos, 65-72 [en línea]: $<$ http://cvc.cervantes.es/ensenanza/biblioteca_ele/asele/pdf/14/14_0066.pdf>. [Consulta: 17/10/2012].

BosQue, Ignacio (2009): «Prólogo», en Nueva gramática de la lengua española, Madrid, Espasa Calpe, XIL-XLVIII.

Bravo GarcíA, Eva María (2008): El español internacional, Madrid, Arco Libros.

NORMAS. REVISTA DE ESTUDIOS LINGÜÍSTICOS HISPÁNICOS, NÚMERO 3 (AÑO 2013):

http://www.uv.es/normas

(ISSN 2174-7245) 
Clyne, Michael, ed. (1992): Pluricentric Languages. Differing Norms in Different Nations, Berlin/New York, De Gruyter.

DEMONTE BARRETO, Violeta (2001): «El español estándar (ab)suelto. Algunos ejemplos del léxico y la gramática», en II Congreso Internacional de la Lengua Española (Valladolid, 2001) [en línea]: $<$ http://cvc.cervantes.es/obref/congresos/valladolid/ponencias/unidad_diversidad_del_es panol/1_la_norma_hispanica/demonte_v.htm>. [Consulta: 12/02/2013].

Di TUlLIO, Ángela L. (2007): «El idioma español: delicado equilibrio entre unidad y diferencias», Desde la Patagonia difundiendo saberes, vol. 4, n. ${ }^{\circ}$ 5, 14-22 [en línea]: <http://www.desdelapatagoniads.com.ar/pdf/numero5/Lengua.pdf>. [Consulta: 22/02/2013].

FAJARDO AGUIRRE, Alejandro (2011): «La norma lingüística del español desde una perspectiva lexicográfica: norma nacional versus norma panhispánica», Normas. Revista de Estudios Lingüísticos Hispánicos, n. ${ }^{\circ}$ 1, 53-70 [en línea]: <http://www.uv.es/normas/2011/Fajardo_2011.pdf>. [Consulta: 12/05/2013].

GARATEA GraU, Carlos (2006): «Pluralidad de normas en el español de América», Revista Internacional de Lingüística Iberoamericana, vol. IV, n. ${ }^{\circ}$ 1, 7, 141158.

GARRIDO, Joaquín (2010): «Lengua y globalización: inglés global y español pluricéntrico», Historia y Comunicación Social, 67-102 [en línea]: <http://www.ucm.es/info/histycom/downloads/05joaquingarrido.pdf >. [Consulta: 15/05/2013].

GóMEZ FONT, Alberto (2012a): «El español global en la prensa del siglo XXI», en Lebsanft/Mihatsch/Polzin-Haumann, eds., El español, ¿desde las variedades a la lengua pluricéntrica?, Madrid/Frankfurt, Iberoamericana/Vervuert (Colección: Lengua y Sociedad en el Mundo Hispánico, 30), 19-26.

GÓMEZ FONT, Alberto (2012b): «Español neutro, global, general, estándar o internacional», Ómnibus, n. ${ }^{\circ}$ 39, Año VIII, mayo 2012 [en línea]: <http://www.omnibus.com/n39/sites.google.com/site/omnibusrevistainterculturaln39/especial/espanolinternacional.html>. [Consulta: 22/05/2013].

Instituto Cervantes (2012): El español en el mundo. Anuario del Instituto Cervantes 2012. Centro Virtual Cervantes [en línea]: $<$ http://cvc.cervantes.es/lengua/anuario/anuario_12/>. [Consulta: 19/04/2013].

LAGARES, Xoán y Maite CELADA (2011): «Política y autoridad linguisticas [sic] Las academias de la lengua en la contemporaneidad. Entrevista a miembros de Academias de la lengua: Adolfo Elizaincín, Ángela Di Tullio, José Luis Moure e Inés Fernández-Ordóñez», Abehache. Revista da Associação Brasileira de Hispanistas, vol. $1,{ }^{\circ}{ }^{\circ} 1,99-107$.

LARA, Luis Fernando (2005): «Para una reconstrucción de la idea de la lengua española. Más allá de las fronteras instituidas», Revista Internacional de Lingüística Iberoamericana, vol. III, n. ${ }^{\circ}$ 2, 6, 171-187. 
Lebsanft, Franz, Wiltrud Minatsch y Claudia Polzin-Haumann, eds. (2012): El español, ¿desde las variedades a la lengua pluricéntrica?, Madrid/Frankfurt, Iberoamericana/Vervuert (Colección: Lengua y Sociedad en el Mundo Hispánico, 30).

LÓPEZ GARCíA, Ángel (2010): Pluricentrismo, hibridación y porosidad en la lengua española, Madrid/Frankfurt, Iberoamericana/Vervuert.

LÓPEZ MORALES, Humberto (2010): La andadura del español por el mundo, Madrid, Taurus.

MARCoS-MARín, Francisco A. (2006): Los retos del español, Madrid/Frankfurt, Iberoamericana/Vervuert.

MÉNDEZ GARCíA DE PAREDES, Elena (2012): «Los retos de la codificación normativa del español: cómo conciliar los conceptos de español pluricéntrico y español panhispánico», en Lebsanft/Mihatsch/Polzin-Haumann, eds., El español, ¿desde las variedades a la lengua pluricéntrica?, Madrid/Frankfurt, Iberoamericana/Vervuert (Colección: Lengua y Sociedad en el Mundo Hispánico, 30), 281-312.

Moreno FERnÁndeZ, Francisco (2005): Historia social de las lenguas de España, Barcelona, Ariel.

MORENO FERNÁNDEZ, Francisco (2010): Las variedades de la lengua española y su enseñanza, Madrid, Arco Libros (Manuales de formación de profesores de español 2/L).

Petrella, Lila (1997): «El español "neutro" de los doblajes: intenciones y realidades», en La lengua española y los medios de comunicación. I Congreso Internacional de la Lengua Española (Zacatecas, 1997) [en línea]: <http://cvc.cervantes.es/obref/congresos/zacatecas/television/comunicaciones/ petre.htm>. [Consulta: 19/10/2012].

Poema de Fernán González. Edición de Juan Victorio, Madrid, Cátedra, 1990, 3. a ed. (Colección Letras Hispánicas).

PÖLL, Bernhard (2012): «Situaciones pluricéntricas en comparación: el español frente a otras lenguas pluricéntricas», en Lebsanft/Mihatsch/Polzin-Haumann, eds., El español, ¿desde las variedades a la lengua pluricéntrica?, Madrid/Frankfurt, Iberoamericana/Vervuert (Colección: Lengua y Sociedad en el Mundo Hispánico, 30), $29-45$.

REAL ACADEMIA EsPañola/Asociación DE ACADEMIAS DE LA LENGUA ESPAÑOLA (2005): Diccionario panhispánico de dudas, Madrid, Santillana.

REAL ACADEMIA ESPAÑOLA/ASOCIACIÓN DE ACADEMIAS DE LA LENGUA ESPAÑOLA (2009): Nueva gramática de la lengua española, 2 vols., Madrid, Espasa Calpe.

Rivarola, José Luis (2006): «El español en el siglo XXI: los desafíos del pluricentrismo», Boletín Hispánico Helvético, vol. 8, 97-109.

ROMERo GuAlDA, M. ${ }^{a}$ Victoria (2008 [1993]): El español en los medios de comunicación, Madrid, Arco Libros.

SÜSELBECK, Kirsten (2012): «Las relaciones institucionales entre las Academias de la Lengua Española y su colaboración en la elaboración de la norma lingüística de 1950 hasta hoy», en Lebsanft/Mihatsch/Polzin-Haumann, eds., El español, ¿desde las 
variedades a la lengua pluricéntrica?, Madrid/Frankfurt, Iberoamericana/Vervuert (Colección: Lengua y Sociedad en el Mundo Hispánico, 30), 257-280.

TEJERA, María Josefina (2003): «La tercera norma del español de América», en Moreno Fernández, Francisco et alii, coords., Lengua, variación y contexto. Estudios dedicados a Humberto López Morales, vol. II, Madrid, Arco Libros, 861-873.

ThOMPSON, Ruth W. (1992): «Spanish as a Pluricentric Language», en Michael Clyne, ed., Pluricentric Languages. Differing Norms in Different Nations, Berlin/New York, De Gruyter, 45-70.

TORRENT-LENZEN, Aina (2006): Unidad y pluricentrismo en la comunidad hispanohablante: cultivo y mantenimiento de una norma panhispánica unificada, Titz, Lenzen.

UEDA, Hiroto (2009): «Resultados y proyectos en las investigaciones sobre variación léxica del español», Dialectologia, 2, 51-80 [en línea]: <http://www.publicacions.ub.edu/revistes/dialectologia2/>. [Consulta: 02/03/2013].

Vergara MARTín, Gabriel María (1986 [1936]): Refranero geográfico español, Madrid, Librería y Casa Editorial Hernando. 